\title{
A negociação do desacordo mitigado como estratégia de (im)polidez por ministros do Tribunal Superior do Trabalho
}

\author{
The negociation of mitigated disagreement as a strategy of (im)politeness by ministers \\ of the Tribunal Superior do Trabalho \\ Rodrigo ALBUQUERQUE* \\ Universidade de Brasília (UnB) \\ Carolina Campos PINTO** \\ Universidade de Brasília (UnB)
}

\begin{abstract}
RESUMO: Neste artigo, analisamos o desacordo mitigado como estratégia de (im)polidez em negociação entre ministros do Tribunal Superior do Trabalho durante as sessões de julgamento, por se tratar de um contexto, potencialmente, conflitivo. Para tanto, o trabalho se enquadra, teoricamente, nas áreas da sociolinguística interacional e da pragmática, e, metodologicamente, na análise da conversação, por concebermos que as estratégias sociopragmáticas se estabelecem na conversa. Em suma, constatamos que a interação entre os ministros do TST revelou grande preocupação por preservar a imagem social dos seus pares, especialmente em situações de divergência, coadunando com a seleção de desacordo mitigado como estratégia.

Palavras-chave: (Im)polidez. Desacordo mitigado. Sessões de julgamento. Contexto jurídico.
\end{abstract}

ABSTRACT: In this article, we analyze the mitigated disagreement as (im)politeness strategy in negotiation between ministers at the Tribunal Superior do Trabalho during the judging sessions, because it is a context, potentially, conflicting. Therefore, the work is framing, theoretically, in the interactional sociolinguistics and pragmatics areas, and, methodologically, in the conversation analysis, because we conceive that sociopragmatics strategies are established in the conversation. In summary, we found that the interaction between ministers of the TST revealed great concern for preservation of the social image of their peers, especially in situations of divergence, in line with the selection of mitigated disagreement as a strategy.

Keywords: (Im)politeness. Mitigated disagreement. Judging sessions. Legal context.

\section{Considerações iniciais}

Locutor e interlocutor, na perspectiva sociointeracional, partilham entre si muito mais do que um uso estritamente linguístico. Esses sujeitos, antes de tudo, negociam e co-constroem sentidos, bem como promovem influência recíproca, haja vista que língua, nesse viés, constitui ação sociodiscursiva, em alusão ao famoso título austiniano: as palavras (não apenas dizem, mas) fazem coisas (AUSTIN, 1975 [1962]). Sob essa

\footnotetext{
* Doutor em Linguística. Universidade de Brasília, Departamento de Linguística, Português e Línguas Clássicas, Brasília-DF. E-mail: rodrigo.albuquerque.unb@gmail.com

** Graduada em Direito. Universidade de São Paulo, São Paulo-SP. Graduanda em Letras-Português (licenciatura). Universidade de Brasília, Brasília-DF. E-mail: carolcp88@gmail.com
} 
ótica, a conversa manifesta, conforme lembram Allen \& Guy (1974, p. 11), não só propriedades físicas e mentais, mas também sociais.

Embora haja nas práticas socioculturais de dado povo espaço para a coconstrução de sentidos e para a influência recíproca entre os atores sociais inscritos em sua comunidade, "normas e convenções para a conversa existem para todas as culturas e situações sociais" (MORGAN, 2010, p. 283). A conversa, assim, abarca um conjunto de ações mutuamente ratificadas e ritualmente governadas (GOFFMAN, 1998 [1964], p. 19), o qual gera consequências para a interação face a face.

As ações humanas se estabelecem, culturalmente, a partir de um cluster de convenção e negociação, o que significa notar, portanto, que agimos guiados por convenções socioculturais com certa liberdade para negociarmos nossas próprias ações. Considerada "o coração da vida social e da interação" (BROWN, 2015, p. 326), a polidez é, em nosso prisma, sempre decorrente de uma avaliação interpessoal.

Ou seja, se dada ação está em sintonia com as normas socioculturais de um povo, ela recebe avaliação positiva e é considerada polida, porém se essa ação contraria tais normas, ela é, em decorrência da avaliação negativa, classificada como impolida (FRASER, 1990, p. 220). A polidez, para Costa (2011, p. 17), pode ser definida como código de conduta social que se expressa de forma distinta em cada cultura. Em suma, é importante frisar que os aspectos socioculturais e avaliativos são fulcrais para a nossa concepção de polidez, pois a avaliação se ancora também a uma referência sociocultural.

Para o embasamento teórico deste artigo, lançamos mão, inicialmente, da teoria de faces (GOFFMAN, 1972 [1967]), que, em síntese, disserta sobre o desejo do interlocutor em preservar a sua própria face e a face do outro. Diante dessa necessidade sociointeracional, surgem os estudos de polidez, altamente influenciados pelo conceito de face, ao recomendarem que o locutor "não seja impositivo, dê opções e seja amigável" com seus interlocutores (LAKOFF, 1973, p. 298); arque com todos os custos interacionais para si e beneficie seus interagentes (LEECH, 1983); e respeite a face positiva (desejo de ser valorizado) e a face negativa (desejo de ter a face preservada), promovendo, respectivamente, a valorização e a preservação da face de seus pares (BROWN; LEVINSON, 1987). 
Em contextos jurídicos, adverte Lakoff (1989), são esperadas, na interação face a face, ações polidas e impolidas. Frente a esse cenário, objetivamos, neste trabalho, analisar o desacordo mitigado como estratégia de (im)polidez em negociação entre ministros do Tribunal Superior do Trabalho durante as sessões de julgamento, por se tratar de um contexto, potencialmente, conflitivo. Esse objetivo gera, por consequência, as seguintes questões de pesquisa: (i) que estratégias de desacordo mitigado foram utilizadas pelos ministros do Tribunal Superior do Trabalho e que efeito elas geraram na interação face a face?; e (ii) que sinais (não) linguísticos os ministros oferecem em reação às estratégias de desacordo enunciadas por seus pares?

No que tange às contribuições de Brown \& Levinson (1987), voltamo-nos, neste trabalho, para as estratégias 5 (Busque o acordo) e 6 (Evite o desacordo), de ameaçar a face diretamente com reparo (polidez negativa), que, de igual modo, se articulam com as recomendações apresentadas nos estudos de polidez já apresentados (cf. LAKOFF, 1973; LEECH, 1983; e BROWN; LEVINSON, 1987). Tal decisão se deu em virtude do potencial conflitivo de nosso contexto de pesquisa, bem como da consequente possibilidade de deparamos com a modalização de estratégias linguístico-discursivas frente à necessidade de desacordo. Este pode constituir ato de impolidez positiva, por infringir o desejo do outro em ser aprovado (CULPEPER, 2005; SIFIANOU, 2012).

Nosso estudo afilia-se, plenamente, à sociolinguística interacional, por concebermos que as ações dos sujeitos são negociáveis e construídas na interação face a face; e na pragmática interpessoal, por nos interessarmos, conforme situa Locher (2013), pelos julgamentos que os interagentes fazem dos atos de fala proferidos por seus pares. Locher \& Graham (2010, p. 2) advertem que a pragmática interpessoal faz interface com a sociolinguística interacional e com outras áreas do discurso, focalizando as relações entre as pessoas e o reflexo de tais relações nas escolhas linguísticodiscursivas.

No que diz respeito ao nosso contexto de pesquisa, Oppenheim (1944, p. 154) chama a atenção para o fato de que "uma das particularidades de qualquer linguagem do direito consiste, portanto, no fato de que a validade de suas sentenças depende não só de condições sintáticas e semânticas, mas também de condições pragmáticas”. Tal constatação justifica a presente investigação, pois, assim como Culpeper (2010, p. 3236) estabelece, devemos avaliar, na conversa, aspectos semânticos e pragmáticos, pois a 
(im)polidez se estabelece não só pela expressão linguística, mas também pelo contexto, o que nos permite avaliar as expressões atenuadoras de desacordo no contexto sob análise.

Assim como Marques (2008, p. 294), consideramos relevante, para avaliarmos o uso de estratégias de (im)polidez no contexto do Tribunal Superior do Trabalho, investigarmos o gênero discursivo em questão. Notamos que está em jogo não apenas o funcionamento do próprio gênero, mas, principalmente, o posicionamento discursivo dos interagentes, marcando, assim, uma relação mais/menos as/simétrica entre eles.

$\mathrm{Na}$ sequência de nosso trabalho, discutiremos as principais contribuições teóricas relacionadas ao desacordo como estratégia de (im)polidez, com posterior apresentação dos procedimentos metodológicos adotados. Em seguida, faremos a análise dos dados gerados, a partir de uma sessão de julgamento do Tribunal Superior do Trabalho, e, ao final, traremos algumas reflexões relativas ao estudo realizado.

\section{O desacordo como estratégia de (im)polidez}

Assim como já apresentamos na seção anterior, nosso trabalho, ancorado nos estudos sociointeracionais e pragmáticos, se dedica à investigação do desacordo mitigado como estratégia de (im)polidez. Na composição de nosso quadro teórico, situamos, especialmente, Goffman (1972 [1967]), Lakoff (1973, 1989), Fraser (1980, 1990), Leech (1983, 2014), Pomerantz (2006 [1984]), Brown \& Levinson (1987), Culpeper (1996, 2005, 2008, 2010), Holmes \& Marra (2004), Locher \& Graham (2010), Culpeper et al. (2003), Sifianou (2012), Briz et al. (2013), Haugh (2013), Locher (2013, 2015) e Albuquerque (2015).

A noção de face, em Goffman (1972 [1967]), se constitui através de dois princípios básicos inerentes à interação cotidiana: nossas ações são constantemente avaliadas pelos nossos pares, e nossa imagem social é construída por meio da avaliação que recebemos e da avaliação que fazemos de nós mesmos. Com base nessa demanda interacional, Goffman (1972 [1967], p. 5) define o termo face como o valor social positivo que uma pessoa reivindica para si mesma pelo padrão de comportamento que os outros reconhecem que ela adotou durante determinado contato. Em suma, face é a imagem de si mesmo delineada em termos de atributos sociais aprovados. 
Ao optarmos por sermos mais ou menos polidos, estamos, antes de tudo, atendendo (ou deixando de atender) às necessidades da face do outro e, por conseguinte, de nossa própria face. Assim, nossa decisão se baseia no gerenciamento quanto aos atos ameaçadores à face (FTAs - face threatening acts). A escolha por valorizar e respeitar a face do outro (e sua imagem pública) é acompanhada por estratégias de polidez, ao passo que a opção por denegrir a face do interlocutor é sinônimo de emprego de estratégias de impolidez. Em sintonia com essa exigência social, é fundamental deixarmos os nossos interlocutores livres em suas ações, sem promovermos quaisquer imposições (LAKOFF, 1973), arcando, portanto, com todo o ônus interacional (LEECH, 1983).

A teoria de Brown \& Levinson (1987) ${ }^{1}$ se vale do conceito de face, na medida em que compreendem possuir a imagem pública, socialmente construída, um aspecto negativo, referente ao espaço de preservação social do sujeito, e um aspecto positivo, relacionado com a autoimagem pública e o desejo de ser apreciado pelos membros de seu grupo social (BROWN; LEVINSON, 1987, p. 66). Brown (2015, p. 326) relembra, com base nesse pensamento, que há, então, dois tipos de polidez: uma que se volta para a valorização/aprovação do outro (polidez positiva), e a outra que preserva o território do outro e visa a atenuar um dizer indesejável (polidez negativa).

Inspirado nas contribuições de Brown \& Levinson (1987), Culpeper (1996) constrói mapeamento do que denomina superestratégias de impolidez, sendo elas: impolidez direta (impolidez cometida diretamente, sem atenuantes); impolidez positiva (uso de estratégias para lesar a face positiva do interagente: infração à necessidade de ser aprovado); impolidez negativa (uso de estratégias para lesar a face negativa do interagente: invasão territorial); impolidez falsa (impolidez sob o formato de uma brincadeira); e ausência de polidez (ausência de polidez quando ela é esperada). Tais estratégias podem se manifestar, reitera o autor (2005, p. 38), por ação intencional do locutor, por percepção do interlocutor ou por ambos os mecanismos, o que significa

\footnotetext{
${ }^{1} \mathrm{Na}$ interação face a face, há atos de fala que são considerados potencialmente ameaçadores à imagem social dos interagentes (FTA ou face-threatening acts). Albuquerque (2015) sistematizou o modelo de Brown \& Levinson (1987), no que tange às opções disponíveis aos interagentes frente aos FTAs, do seguinte modo: ameaçar a face diretamente; ameaçar a face diretamente com reparo (valorizando o interlocutor - polidez positiva); ameaçar a face diretamente com reparo (evitando a imposição - polidez negativa); ameaçar a face indiretamente; e não ameaçar a face.
} 
querer ser impolido (ação intencional) ou não ter consciência de ser impolido (percepção do outro).

Determinado ato pode ser considerado (im)polido, segundo Culpeper (2008, p. 30), a partir de quatro normas: individuais, culturais, situacionais e co-textuais. Frente ao ato de fala impolido, podemos não responder; responder e aceitar o ato impolido; responder e reagir com defesa; e responder e reagir com ofensa (CULPEPER et al., 2003, p. 1562-3).

De modo similar, Terkourafi (2005) acrescenta que a avaliação de atos polidos se dá com base na co-ocorrência regular de determinadas expressões linguísticas em contextos particulares, havendo, a partir dessa regularidade, a percepção de dado ato como polido. Adicionalmente, ratifica Meier (1995, p. 352), tal avaliação ocorre com base nos pressupostos culturais, que regulam a produção e a compreensão de determinadas estratégias linguísticas. Em outras palavras, quando escolhemos o modo como vamos nos comportar, estamos nos posicionando em relação às normas da comunidade de prática à qual nos integramos (GRAHAM, 2007, p. 743).

Conceituar a (im)polidez como prática social implica considerarmos que as ações sociais e os significados pragmáticos não são apenas inerentes às múltiplas interações face a face, eles são, antes de tudo, semioses inexoravelmente morais (HAUGH, 2013, p. 57). Em congruência com Haugh (2013, p. 59), nossa perspectiva de (im)polidez ancora-se às práticas sociais dos sujeitos, uma vez que compactuamos com a ideia de que teorizar a polidez demanda focalizarmos as avaliações decorrentes das ações sociais e dos sentidos veiculados por estas, ambos reconhecidos pelos interlocutores, por estarem inseridos nas práticas interacionais que as regulam.

Não é incomum que, durante a conversa, precisemos violar uma máxima para cumprirmos com outra. É o que parece acontecer entre a máxima da qualidade e a máxima da polidez. Albuquerque (2015, p. 45-6) comenta que escolher uma pode acarretar a infração de outra, diante do dilema entre ser verdadeiro e ser polido, especialmente no contexto brasileiro, em que a sinceridade pode, por vezes, constituir falta de polidez. A mitigação de atos impolidos pode, talvez, atenuar esse conflito interacional, haja vista que podemos, concomitantemente, ser verdadeiros e mitigar a impolidez com suavizadores linguístico-discursivos. 
A teoria da mitigação, proposta por Martinovski et al. (2005), contempla uma avaliação de atos de fala realizada pelos interagentes, com base em mecanismos sociocognitivos e pragmático-discursivos. O primeiro processo (avaliação) requer do locutor e do interlocutor, diante de um evento real/potencial, o exame de duas necessidades pragmáticas: proteger a face e manter a polidez, e estabelecer reações de defesa mediante acusações. A partir de tais necessidades, provenientes de situações interacionais conflitivas, os sujeitos desenvolvem, no último processo (mitigação), estratégias de manejo, estabelecidas discursivamente, que originarão, por meio de processos cognitivos e de padrões linguísticos, argumentos e ações. Esses argumentos e essas ações podem, a depender da experiência social dos interagentes, passar por um processo de reavaliação, retornando, assim, ao início do ciclo.

Linguisticamente, a atenuação consiste em "diminuir, minimizar, mitigar, debilitar a ação e a intenção ou o efeito que estas possam ter ou ter tido na interação" (BRIZ et al., 2013, p. 285), podendo estar envolvidos os interagentes e, inclusive, os terceiros (presentes ou ausentes). Discursivamente, prosseguem Briz et al. (2013, p. 286), a atenuação constitui mecanismo estratégico de distanciamento linguístico da enunciação (indiretividade), com a finalidade de promover maior aproximação social entre os interagentes (conforto interacional).

As estratégias de mitigação de atos impositivos, discutidas por Briz et al. (2013, p. 288-92), são a despessoalização (ocultação do responsável pelas ações, com estratégias que buscam generalizá-lo) e a relativização (indeterminação do que se expressa, com estratégias mais indiretas, hipotéticas). Em consonância com Briz et al. (2013, p. 294), compreendemos, ainda, que o ato de atenuar é mais frequente em situações de formalidade e de maior planejamento discursivo, como no caso do nosso contexto de pesquisa. Nos cenários jurídicos, o uso de expressões mitigadoras associase à autodefesa e à defesa, sem que o interagente, todavia, negue sua responsabilidade pelo ato de fala enunciado (MARTINOVSKI, 2006, p. 2066), de modo a "aliviar antecipadamente o efeito indesejado" (FRASER, 1980, p. 341) da enunciação.

Uma polidez solidária, na concepção de Brown (2015, p. 327), caracteriza-se pela ênfase no acordo e pela esquiva do desacordo. O desacordo pode ser veiculado diretamente: quando houver menor distância social entre os interagentes, quando o 
locutor detiver maior poder em relação a seu interlocutor e quando a intensidade do desacordo for menor (não constituir ato impositivo) (BROWN; LEVINSON, 1987).

Brown \& Levinson (1987, p. 117-21) listam algumas estratégias para buscarmos o acordo na conversa: a seleção de tópicos seguros, nos quais é possível concordar com o interlocutor; a repetição do que o interlocutor acabou de dizer numa conversa, como estratégia também de reforço; a utilização de sinais de acordo (token agreements) em situações nas quais há, na verdade, desacordo; o pseudo-acordo, para assinalar que o interagente pretende chegar a um acordo cooperativamente construído com o interlocutor; as mentiras brancas, com o intuito de preservar a face positiva do interlocutor; e a atenuação da opinião, na escolha pela vagueza, a fim de mitigar o desacordo. Os diferentes níveis de manifestação do desacordo, para Brown \& Levinson (1987), podem ser sistematizados no seguinte continuum polidez-impolidez:

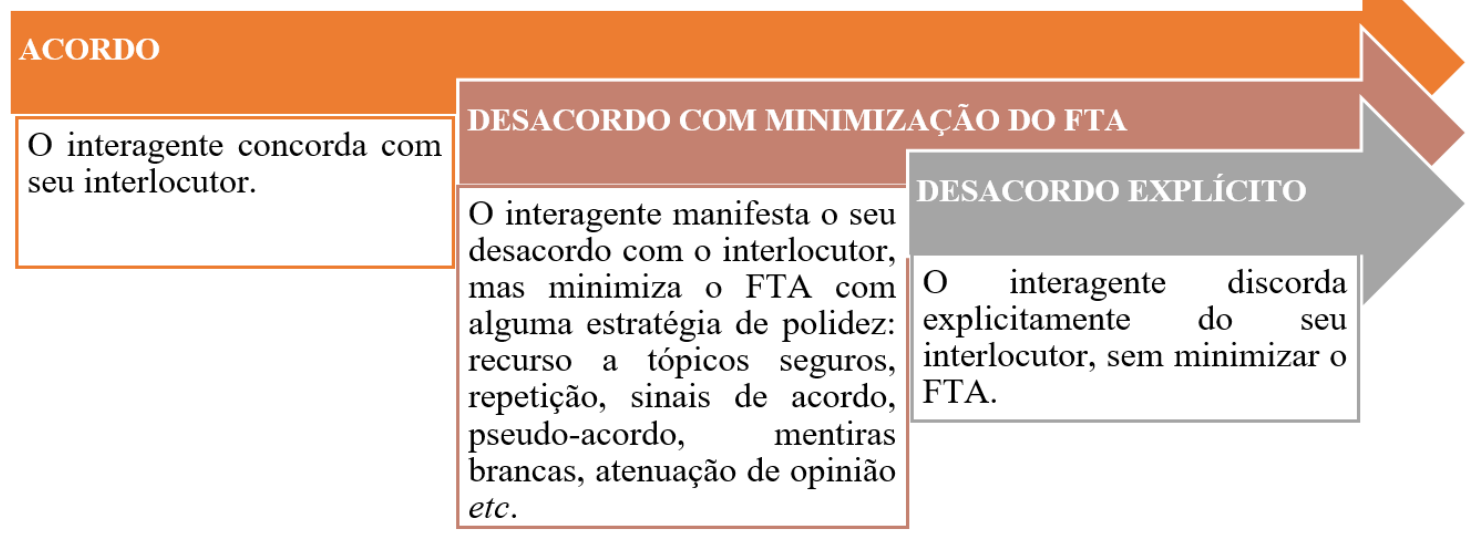

Figura 1: Continuum polidez-impolidez elaborado por nós, com base nas estratégias Buscar o acordo e Evitar o desacordo, de Brown \& Levinson (1987).

Ao tratar das máximas de polidez, Leech (1983, p. 138) situa a máxima do acordo, que é negociada pelos interlocutores ao assumirem ações de intensificar o acordo ou de mitigar o desacordo (por meio de acordo parcial ou de expressão de arrependimento). O autor (1983), em linhas gerais, postula que o locutor deve arcar com todos os custos interacionais para si e, ao mesmo tempo, poupar/beneficiar seu interagente $^{2}$. O desacordo, para ele, seria ato impolido, uma vez que tal ação geraria

\footnotetext{
${ }^{2}$ A obra de Leech, publicada em 2014, realiza uma série de reavaliações quanto ao trabalho pioneiro do autor, proposto em 1983. Leech (2014, p. 90-1) questiona a própria nomenclatura empregada (máxima), que rememora um caráter restritivo e polarizado/binário (o sujeito, por exemplo, concorda ou discorda), e propõe uma Estratégia Geral de Polidez [General Strategy of Politeness], que recomenda, em
} 
custos ao interagente; o acordo, por sua vez, constituiria ato polido, por preservar a face do outro.

Neste trabalho, não associamos, categoricamente, o acordo à polidez, e o desacordo à impolidez, tendo em vista o caráter sociocultural e contextualmente situado de nosso estudo. Ademais, em harmonia com Sifianou (2012, p. 1559), pressupomos ser o desacordo multidirecional (por se voltar para a(s) face(s) do(s) interagente(s)) e multifuncional (por abarcar várias funções, inclusive marcar hostilidade e afiliação).

Em trabalho posterior, o próprio Leech $(2014$, p. 203) admite a relatividade na avaliação dos atos (im)polidos, ao constatar, por exemplo, que o silêncio após um enunciado como Estou ficando gordo indicaria acordo e seria considerado impolido. Para Haugh (2013, p. 53), as ações linguístico-discursivas podem ser avaliadas como "polidas, não polidas, não impolidas, impolidas, falsamente impolidas, falsamente polidas, nem polidas nem impolidas, além de polidas e assim por diante".

Acreditamos, tal qual Watts (2005, xiii), que "a polidez sempre será uma qualidade de interação instável e, por fim, indefinível, sujeita a mudanças no tempo e no espaço cultural". Destacamos que nenhuma avaliação dos atos ameaçadores à face é linear, pois a tolerância a tais atos varia em relação às situações e aos gêneros do discurso (KERBRAT-ORECCHIONI, 2014, p. 77), bem como aos pressupostos socioculturais.

No que se refere à manifestação do acordo ou do desacordo, Pomerantz (2006 [1984], p. 64) defende que uma ação, em virtude das expectativas dos participantes da comunicação, será escolhida e realizada de tal forma que reflita a orientação dos participantes. Isto é, há uma relação entre o status de preferência da ação e a forma como ela é produzida.

Em se tratando de expectativas, Marques (2008, p. 278) sugere que a agressividade no discurso jurídico, inerente a um gênero discursivo agonal (não consensual), é disciplinada pelos códigos de conduta do Tribunal, visando, concomitantemente, à preservação das faces dos interagentes e à obediência a um discurso institucional. A autora (2008) ressalta ser previsível a ritualização parlamentar nos debates, que portam atos de fala potencialmente agressivos, porém a própria

atendimento à máxima do acordo, darmos maior valor às opiniões alheias e menor valor às nossas próprias. 
interação face a face, antes de tudo, convoca "a negociação e o cuidado das imagens dos interlocutores" (MARQUES, 2008, p. 278).

Embora o desacordo seja absolutamente comum em nossas atividades cotidianas, sua força, asseguram Angouri \& Locher (2012, p. 1549), depende dos interlocutores envolvidos, do tópico conversacional em questão, das repercussões geradas nas relações interpessoais e das normas convencionalizadas pela comunidade. $\mathrm{O}$ desacordo pode ser determinado a depender das histórias dos participantes, da finalidade do evento no qual estes estão inscritos e do (des)equilíbrio de poder entre esses atores sociais, porém em constante renegociação e construção conjunta, consoante ao contexto em que ocorre a experiência interacional (ANGOURI, 2012, p. 1576).

De modo geral, as razões que motivam os sujeitos a manifestarem (des)acordo servem, segundo Graham (2007, p. 743), para termos acesso ao modo como as relações se estabelecem dentro dos grupos. Sifianou (2012, p. 1558) esclarece, nesse sentido, que os desacordos emergentes de dada interação podem ter sua gênese em interações anteriores, e não apenas no turno conversacional que precedeu a enunciação do interlocutor, o que impossibilita ao analista ter pleno acesso ao que, de fato, motivou o desacordo no enunciado.

Pomerantz (2006 [1984]) propõe avaliações relativas ao acordo e ao desacordo situadas em um continuиm. O acordo, segundo a autora (2006 [1984], p. 248-50), pode ser intensificado (termo avaliativo mais forte); semelhante (termo avaliativo repetido); e suavizado (termo avaliativo menos intenso). Já o desacordo, avança Pomerantz (2006 [1984], p. 251), manifesta-se no atraso de resposta com silêncio, no pedido de esclarecimento, na repetição parcial do que foi dito, na utilização de reparadores para preparar o desacordo e no início de desacordo. O continuum, assim como destaca Albuquerque (2015, p. 253), ocorre na medida em que a avaliação varia, no acordo, de uma intensificação (acordo intensificado) a uma suavização (um quase desacordo); e no desacordo, de uma estratégia mais sutil de discordância (atraso na resposta com silêncio) a um pleno desacordo (início de desacordo).

Ao investigar o uso da linguagem no local de trabalho, Holmes \& Marra (2004, p. 441) notaram que os gestores, em situações de desacordo, empregavam diversos recursos, que variavam do menos conflitivo ao mais conflitivo, a saber: (a) evitação de conflitos [conflict avoidance]; (b) desvio de conflitos [conflict diversion]; (c) resolução 
de conflitos usando negociação [conflict resolution using negotiation]; e (d) resolução de conflitos usando autoridade [conflict resolution using authority]. No gerenciamento de tais recursos, os gestores buscavam, na sequência das ações apresentadas, afirmar a agenda, afastar conflitos, trabalhar no conflito e impor uma decisão.

Para a nossa análise, buscaremos utilizar as reflexões aqui apresentadas, com especial atenção às taxonomias produzidas por Briz et al. (2013), no estudo da mitigação; e por Brown \& Levinson (1987), Pomerantz (2006 [1984]) e Holmes \& Marra (2004), no estudo do (des)acordo.

\section{As reflexões e as ações metodológicas}

Elegemos a análise da conversação como orientação metodológica devido ao interesse da área pela descrição dos mecanismos linguístico-discursivos, presentes na interação, funcionado, conforme destaca Schegloff (2006 [1991], p. 88), como instrumento voltado para as ações e para as práticas sociais. Outra razão para tal escolha é a forte interface que ela possui com a pragmática e com a sociolinguística (CLIFT et al., 2006).

$\mathrm{Na}$ visão de Locher (2015, p. 8), os estudiosos podem, a depender de suas questões de pesquisa, combinar ferramentas metodológicas e/ou percepções teóricas no desvelamento de dada prática social ou de normas pessoais, culturais, situacionais, cotextuais e ideológicas, que permeiam a interação face a face, como optamos neste estudo.

Segundo Marcuschi (1999, p. 7), a análise da conversação busca compreender como as pessoas se entendem ao conversar, ou seja, como sabem que estão agindo de forma coordenada e cooperada, como usam seus conhecimentos linguísticos para criar condições adequadas à compreensão mútua, como eventualmente resolvem conflitos interacionais (o que inclui o gerenciamento de estratégias de (im)polidez).

Kerbrat-Orecchioni (2006 [1943], p. 15) acrescenta que o objetivo da análise da conversação consiste em trazer à tona as "regras que sustentam o funcionamento das trocas comunicativas de todos os gêneros". Tal escopo compatibiliza-se com nossa meta, uma vez que procederemos com a análise de um excerto interacional, composto por estratégias que sinalizam desacordo mitigado em uma sessão de julgamento da 
Subseção I Especializada em Dissídios Individuais (SBDI-1), órgão integrante do Tribunal Superior do Trabalho ${ }^{3}$.

A SBDI-1 naturalmente representa espaço de discussão de posições jurídicas divergentes, seja em razão das diferentes formações pessoais e profissionais dos ministros que a compõem, seja pelo fato de que estes integram diferentes Turmas, que podem já ter posição definida sobre uma questão e se veem desafiados pela ocorrência de divergência jurisprudencial. O conflito, como uma das dimensões conversacionais, marca algum processo de falha a ser examinado pela análise da conversação, por meio da investigação das ferramentas presentes na interação verbal (ALLEN; GUY, 1974, p. 239).

Nesse sentido, esta pesquisa, assim como já apresentamos na seção introdutória, visa a analisar o desacordo mitigado como estratégia de (im)polidez em negociação entre ministros do Tribunal Superior do Trabalho durante as sessões de julgamento, por se tratar de um contexto, potencialmente, conflitivo. Para tanto, valemo-nos da avaliação que os interlocutores fazem de seus atos de fala, com base na organização preferencial pelo desacordo mitigado no excerto interacional analisado na seção seguinte. O termo organização preferencial, bastante utilizado pelos analistas da conversação, refere-se a uma série de práticas conversacionais que são gerenciadas pelos interagentes, promovendo, como resultado de suas escolhas, afiliação ou distanciamento interacional (HERITAGE; RAYMOND, 2005; HOLTGRAVES, 1992; LERNER, 1996; POMERANTZ, 2006 [1984]; SCHEGLOFF, 1988; SCHEGLOFF et al., 1977).

Pretendemos, assim como Marcuschi (1989), analisar os marcadores conversacionais, por serem multifuncionais, ou seja, abarcarem as funções de organizadores interacionais, articuladores textuais e indicadores de força ilocutória (MARCUSCHI, 1989, p. 282). Tais marcadores nos permitem compreender nuances quanto à forma como os ministros interagiam entre si durante os debates.

Com o objetivo de ancorar esta pesquisa a fontes confiáveis, os dados analisados são provenientes da gravação do julgamento do processo $\mathrm{n}^{\circ}$ E-ED-RR-65820089.2009.5.09.0670 na sessão da SBDI-1, de 12/05/2016, disponível no canal do TST no

\footnotetext{
${ }^{3}$ A Subseção I Especializada em Dissídios Individuais (SBDI-1) constitui órgão fracionário do TST, cuja principal função consiste em uniformizar a jurisprudência trabalhista de todo o país, em casos de divergência jurisprudencial nas decisões de diferentes Turmas do TST.
} 
sítio eletrônico YouTube. Por essa razão, foi possível assistir ao julgamento mais de uma vez, a fim de selecionarmos os trechos que apresentavam manifestações de desacordo mitigado como estratégia de (im)polidez utilizadas pelos ministros durante o debate, bem como analisar detidamente os marcadores conversacionais linguísticos e não linguísticos que pudessem surgir.

O corpus de dados foi constituído com base na técnica de saturação, segundo a qual "interrompe-se a coleta de dados quando se constata que elementos novos para subsidiar a teorização almejada (ou possível naquelas circunstâncias) não são mais depreendidos a partir do campo de observação" (FONTANELLA et al., 2011). Desse modo, o trecho do julgamento ora analisado foi selecionado por ser o mais representativo das estratégias estudadas e por responder às questões de pesquisa propostas na seção introdutória.

\section{Debate na sessão de julgamento da SBDI-1}

O julgamento a ser analisado, relativo ao processo $\mathrm{n}^{\circ}$ E-ED-RR-65820089.2009.5.09.0670, discutiu a solução que deveria ser dada ao recurso de uma empresa que figurava como ré em ação civil pública ajuizada pelo Ministério Público do Trabalho, pelo suposto descumprimento da lei que previa a contratação de um número mínimo de empregados portadores de necessidades especiais.

Embora todos os ministros da SBDI-1 concordassem que a empresa não tinha descumprido a lei, uma vez que havia envidado todos os esforços para contratar os empregados portadores de necessidades especiais, alguns deles divergiram relativamente à solução processual a ser dada ao caso, entendendo que a procedência total do recurso empresarial poderia ser interpretada como a dispensa da obrigação da empresa em cumprir a lei em situações futuras.

O Ministro Relator, a quem cabia a primeira análise do recurso, inicialmente havia votado pela procedência total do recurso empresarial, mas, imediatamente antes da interação analisada a seguir, informou que havia alterado seu voto para a procedência parcial. 
/.../

\begin{tabular}{|c|c|c|}
\hline $\begin{array}{l}1 \\
2 \\
3 \\
4 \\
5 \\
6 \\
7 \\
8 \\
9 \\
10 \\
11\end{array}$ & Min. Valter & $\begin{array}{l}\text { presidente (.) é o ministro Valter (.) não é bem uma divergência talvez aqui (.) } \\
\text { eh: uma ponderação (.) Sua Excelência o ministro relator diz no seu voto (.) } \\
((+)) \text { muito bem fundamentado como sempre que "conquanto seja ônus da } \\
\text { empresa cumprir a exigência prevista na lei (.) ela não pode ser responsabilizada } \\
\text { pelo insucesso } \downarrow \text { (.) quando ficou comprovado que envidou esforços para } \\
\text { preencher a cota MÎnima sendo indevida a multa bem como não havendo falar } \\
\text { em dano moral coletivo" eu estou de acordo (ac.) pleno acordo (.) mas se a } \\
\text { empresa está cumprindo a lei } \uparrow(.) \text { e envidou esforços para cumprir a lei não seria } \\
\text { um provimento absolutório (.) total } \uparrow(. .) \text { como manter a obrigação (.) se essa } \\
\text { obrigação já é prevista na lei (.) não seria então ao invés de parcial provimento } \\
\text { total } \uparrow(.)((\text { movimento circular com as mãos)) essa era a dúvida }\end{array}$ \\
\hline 12 & Iin. Ivan & que era era / na verdade era o voto inicial do ministro Bastos \\
\hline 13 & Min. Valter & era esse né $((\mathrm{R}))$ eh: eu $((\mathrm{R}))$ era isso ministro Bastos $\downarrow$ \\
\hline $\begin{array}{l}14 \\
15 \\
16 \\
17 \\
18 \\
19 \\
20 \\
21 \\
\end{array}$ & Min. Basto & $\begin{array}{l}\text { o raciocínio do ministro /do ministro eh: Valter } \uparrow \text { eh: sempre muito / sempre (.) } \\
\text { MUITO Lúcido e era essa a ideia } \uparrow \text { mas o que: me: moveu aqui foi esclarecer } \uparrow(.) \\
\text { esclarecer que essa improcedência não significa que a lei não al / que a empresa } \\
\text { não esteja eh: ((movimento circular com as mãos)) dentro daqueles parâmetros } \\
\text { que a lei prevê (.) porque a empre- ah ah / o trânsito em julgado de uma decisão } \\
\text { dessa dizendo pela improcedência (.) eh eu não saberia dizer melhor (.) eh } \\
\text { limitar melhor essa improcedência } \downarrow \text { mas eu agradeço a Vossa Excelência (ac.) }\end{array}$ \\
\hline $\begin{array}{l}22 \\
23 \\
24 \\
25 \\
26 \\
27 \\
28 \\
29 \\
30\end{array}$ & Min. Valter & $\begin{array}{l}\text { não eu entendi (.) Vossa Excelência está de certo modo } \downarrow \text { (.) concedendo uma } \\
\text { tutela inibitória } \uparrow \text { no sentido na verdade de inibir positivamente } \uparrow \text { não é }((+)) \text { que } \\
\text { ela eh: continue a cumprir a lei (.) que ela segundo consta } \downarrow \text { está cumprindo (.) } \\
\text { agora a minha dúvida é se depois ((aponta com o indicador para frente)) / eu já } \\
\text { estou pensando (ac.) / o Ministério Público não vai entender que há uma espécie } \\
\text { de con-tra-di-ção porque obriga a empresa / eu não estou dizendo que há } \\
\text { contradição, ministro Bastos (ac.) / que obriga diz que diz que a empresa } \\
\text { cumpriu a lei e ao mesmo tempo absolve porque ela cumpriu } \downarrow \text { (.) é só essa } \\
\text { dúvida ((palma voltada ao interlocutor)) }\end{array}$ \\
\hline 31 & van & ministro Bastos (.) ministro Bastos e ministro Valter (.) a minha preocupação / \\
\hline $\begin{array}{l}32 \\
33 \\
34\end{array}$ & Min. Valter & $\begin{array}{l}{[[\text { mas eu / olha ministro } \uparrow \text { eu estou acompanhando (.) eu só }} \\
\text { estava ponderando (.) se a equação é para resolver o problema } \uparrow \text { eu estou } \\
\text { acompanhando } \downarrow \text { não estou divergindo } \downarrow\end{array}$ \\
\hline $\begin{array}{l}35 \\
36 \\
37 \\
38 \\
39 \\
40 \\
41\end{array}$ & an & $\begin{array}{l}\text { a minha preocupação quando vi (.) a o dispositivo do voto do ministro Bastos eh } \\
\text { / e-e-e ambos viemos do Ministério Público/ eh: sempre que há uma ação civil } \\
\text { pública e que se postula uma obrigação de fazer ou não fazer (.) é cominatória } \downarrow \\
\text { (.) então eh assim o que me eh estranhou um pouquinho nessa solução final (.) } \\
\text { foi "mantendo no entanto a obrigação da empresa de promover a admissão de } \\
\text { pessoas com deficiência" (.) foi então feito / foi feita essa postulação na ação } \\
\text { civil pública e com alguma cominação } \downarrow\end{array}$ \\
\hline
\end{tabular}

$$
\text { /.../ }
$$

No primeiro turno conversacional (linha 1 a 11), o ministro Valter já apresentou, à linha 1, uma estratégia a qual visava à reparação de futuros desacordos que iriam ocorrer (não é bem uma divergência talvez aqui). Notamos que o interagente relativizou (cf. BRIZ et al., 2013) sua enunciação ao empregar os marcadores discursivos bem e talvez, que sinalizavam mitigação do desacordo (não era uma divergência legítima,

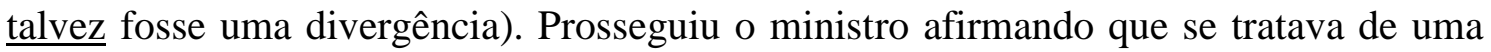
ponderação (linha 2), em acréscimo à mitigação do desacordo, seguida de reforço à face 
positiva de seu interlocutor (o ministro Ivan), ao utilizar o elogio muito bem fundamentado como sempre, à linha 3, corroborado, anteriormente, pelo aceno positivo de cabeça (linha 2). O elogio e o sinal não linguístico funcionaram como reparadores, com a finalidade de preparar o desacordo (cf. POMERANTZ, 2006 [1984]), uma vez que o ministro Valter pretendia mitigar o desacordo, em decorrência de ter, sutilmente, enunciado que sua opinião divergia da opinião do colega.

Ainda no mesmo turno, entre as linhas 3 e 7, o ministro Valter começou a leitura do voto do ministro Ivan, simulando, com isso, a repetição do que ele acabara de dizer (cf. BROWN; LEVINSON, 1987), lançando mão, para tanto, de uma estratégia de acordo. Porém tal estratégia intencionava mitigar ainda mais o desacordo que estava sendo proferido. Na sequência, à linha 7, o ministro disse eu estou de acordo, pleno acordo, mas, o que anunciava um token agreement (cf. BROWN; LEVINSON, 1987) e o uso de reparadores para preparar o desacordo (cf. POMERANTZ, 2006 [1984]). A conjunção mas daria início ao desacordo, anteriormente mitigado, pela aproximação de estrutura concessiva (relativização - cf. BRIZ et al., 2013). Logo, o enunciado do ministro introduzia, de forma mitigada, o desacordo.

Ao fim do turno conversacional do ministro Valter, ele empregou, por duas vezes, a estratégia de relativização, por meio da modificação de verbos performativos na forma temporal (cf. BRIZ et al., 2013), devido ao fato de ter enunciado que não seria um provimento absolutório (linhas 8 e 9) e não seria então (linha 10). Sua opção revelava não ter desejado afirmar categoricamente, mas conferir um status hipotético, deixando o espaço das certezas para o outro ministro, dado que visava a preservar a face deste. À última linha do turno conversacional (linha 11), o ministro manteve as estratégias adotadas entre linhas 8 e 10, e encerrou seu turno, ao sugerir um pedido de esclarecimento (cf. POMERANTZ, 2006 [1984]) quando expressou essa era a dúvida, tencionando, com essa ação, mitigar o desacordo. A palavra dúvida (linha 11), de sua enunciação, colaborava ainda mais com a ação mitigada.

Após a resposta do ministro Ivan (segundo turno conversacional - linha 12), o ministro Valter procurou estabelecer, no terceiro turno conversacional (linha 13), um pseudo-acordo (cf. BROWN; LEVINSON, 1987) com o uso do marcador discursivo de controle de contato (cf. BRIZ et al., 2013) né, seguido de risada amistosa. 
Ao assumir o quarto turno conversacional (linha 14 a 21), o ministro Bastos procurou atender aos desejos da face positiva do ministro Valter, quando proferiu elogios ao raciocínio dele e, por conseguinte, ao próprio colega: o raciocínio do ministro Valter é sempre muito lúcido mas (linhas 14 e 15). O ministro Bastos optou por usar, assim como seu colega, o elogio como reparador, a fim de preparar o desacordo (cf. POMERANTZ, 2006 [1984]) que seria iniciado pela conjunção mas, na veiculação de estrutura concessiva (relativização - cf. BRIZ et al., 2013). A repetição do item lexical esclarecer, entre as linhas 15 e 16, em adição ao que Bastos declarou às linhas 19 e 20 (eu não saberia dizer melhor), colocam-no em posição favorável quanto à preservação da face do outro, uma vez que o ministro utilizou a máxima da modéstia ${ }^{4}$ (cf. LEECH, 1983), com vistas a mover para si os custos interacionais, maximizando, assim, o elogio ao seu interagente. Em outras palavras, Bastos acabou por mitigar o desacordo, pois sugeriu que ele não era capaz de compreender aquele contexto sozinho, tampouco se expressar, valorizando, dessa forma, a face de seu interlocutor no uso do elogio como estratégia.

Chegando ao quinto turno conversacional (linha 22 a 30), constatamos que o ministro Valter parcialmente repetiu, à linha 23, a estratégia adotada à linha 13: o pseudo-acordo (cf. BROWN; LEVINSON, 1987) e o uso de marcadores discursivos para controle de contato (cf. BRIZ et al., 2013) na expressão não é, porém com o aceno positivo de cabeça. Em o Ministério Público não vai entender que há uma espécie de contradição porque obriga a empresal eu não estou dizendo que há contradição, ministro Bastos (entre as linhas 26 e 28), o interlocutor assumiu movimento de reformulação no que havia dito (relativização - cf. BRIZ et al., 2013), ao fazer uso de token agreement (cf. BROWN; LEVINSON, 1987) e de reparador para preparar o desacordo (cf. POMERANTZ, 2006 [1984]), a fim de atenuar o desacordo gerado inicialmente. No fim desse turno, Valter, mais uma vez, encerrou o que tinha para dizer com a sugestão de pedido de esclarecimento (cf. POMERANTZ, 2006 [1984]) em é só essa dúvida (linhas 29 e 30), atenuando, ainda mais, o desacordo com o uso do recurso intraproposicional de quantificação só.

\footnotetext{
${ }^{4}$ A máxima da modéstia, descrita por Leech (1983), segue o mesmo princípio geral proposto pelo autor: arcar com os custos interacionais para si e beneficiar os interagentes. Nessa linha de pensamento, Leech (1983, p. 136) aconselha minimizar o autoelogio e maximizar o elogio ao outro.
} 
Após o sexto turno conversacional (linha 31), o ministro Valter reassumiu a vez de falar (no sétimo turno conversacional - linha 32 a 34) e reforçou, entre as linhas 32 e 34, a mitigação do desacordo com estratégia similar à encontrada entre as linhas 26 e 28. Ao escolher enunciar eu estou acompanhando (linha 32), eu só estava ponderando (linhas 32 e 33) e eu estou acompanhando não estou divergindo (linhas 33 e 34), o ministro acabava prosseguindo com o movimento de reformulação em relação ao que havia dito entre as linhas 26 e 28 (relativização - cf. BRIZ et al., 2013), por veicular um token agreement (cf. BROWN; LEVINSON, 1987) e um reparador para preparar o desacordo (cf. POMERANTZ, 2006 [1984]), e por simular que não desejava divergir, apesar de ter apresentado argumentos contrários de forma mitigada, ao ter insinuado anteriormente que havia uma espécie de contradição (linhas 26 e 27).

Por fim, no oitavo turno conversacional (linha 35 a 41), o ministro Ivan utilizou, à linha 38, o diminutivo pouquinho, como recurso intraproposicional (cf. BRIZ et al., 2013), com o propósito de atenuar a sua opinião (cf. BROWN; LEVINSON, 1987) de que aquela situação toda lhe causava estranhamento. Seu desejo consistia, assim, em caracterizar a estranheza com relação ao voto do ministro Bastos. À linha 39, Ivan decidiu lançar mão da despessoalização (cf. BRIZ et al., 2013), por meio da construção nominal solução final, e de certa vagueza referencial (cf. BROWN; LEVINSON, 1987), com a finalidade de atenuar a crítica ao voto do Ministro Relator, fazendo referência não à sua pessoa, mas à solução final proposta.

Por fim, notamos, durante todo o excerto, uma tentativa de resolução de conflitos usando negociação (cf. HOLMES; MARRA, 2004), dado que os ministros, em tese, dispunham de uma relação pouco assimétrica, o que permitia tal escolha. Percebemos, nessa interação, a marcante tendência de os ministros atenuarem a discordância, embora não deixassem de manifestá-la, minimizando, com diferentes estratégias, eventuais danos à face dos colegas de Turma.

\section{Considerações finais}

Devido ao fato de o contexto jurídico contemplar práticas sociais compatíveis com a necessidade de, por vezes, estabelecer desacordo, nosso estudo se voltou para a 
análise de um excerto interacional que pudesse reunir situações de divergências e de potenciais ameaças às faces dos interagentes.

A análise do excerto interacional demonstrou a prevalência de estratégias de mitigação do desacordo, por despessoalização e relativização (cf. BRIZ et al., 2013); por emissão de sinais de acordo (mesmo em situações de desacordo - token agreement), de pseudo-acordo, de repetição do conteúdo anteriormente expresso e de atenuação de opinião (cf. BROWN; LEVINSON, 1987); e por pedido de esclarecimento e uso de reparadores para preparar o desacordo (cf. POMERANTZ, 2006 [1984]).

Esperamos que, de algum modo, esta pesquisa possa inspirar trabalhos futuros, no que tange, especialmente, ao uso de outras estratégias de (im)polidez associadas ao desacordo mitigado, como, por exemplo, o elogio, presente nos dados analisados. O contexto jurídico, evidentemente, é bastante amplo e comporta uma análise da negociação do desacordo por outros interlocutores, com relações ainda mais assimétricas do que a encontrada entre os ministros do TST.

\section{REFERÊNCIAS}

ALBUQUERQUE, R. Um estudo de polidez no contexto de L2: estratégias de modalização de atos impositivos por falantes de espanhol. 2015. 372f. Tese (Doutorado em Linguística) - Programa de Pós-Graduação em Linguística, Universidade de Brasília, Brasília, 2015.

ALlEN, D. E.; GUY, R. F. Conversational Analysis: The Sociology of Talk. Paris, Mouton: 1974.

ANGOURI, J. Managing disagreement in problem solving meeting talk. Journal of Pragmatics, v. 44, p. 1565-53, 2012.

; LOCHER, M. A. Theorising disagreement. Journal of Pragmatics, v. 44, p. 1549-79, 2012.

AUSTIN, J. L. How to do things with words. Oxford: Oxford University Press, 1975 [1962].

ATKINSON, J. M.; HERITAGE, J. Jefferson's transcript notation. In: JAWORSKI, A.; COUPLAND, N. The Discourse Reader. 2nd ed. USA: Routledge, 2006 [1984].

BRIZ, A. et al. A atenuação e os atenuadores: estratégias e táticas. In: Linha D'Água, São Paulo, v. 26, n. 2, p. 281-314, dec. 2013. Disponível em: <http://www.revistas.usp.br/linhadagua/article/view/64415>. Acesso em: 12 set. 2016.

BROWN, P. Politeness and Language. International Encyclopedia of the Social \& Behavioral Sciences, v. 18, p. 326-330, 2015. 
; LEVINSON S. Politeness: some universals in language usage. Cambridge: Cambridge University Press, 1987.

CLIFT, R.; DREW, P.; HUTCHBY, I. Conversation Analysis. In: ÖSTMAN, J. O.; VERSCHUEREN, J. Handbook of Pragmatics. Amsterdam/Philadelphia: John Benjamins, 2006.

COSTA, V. L. de M. A divergência na academia: estratégias discursivas de proteção e de preservação de imagens sociais. Horizontes de Linguística Aplicada, v. 10, n. 2, p. 15-40, jul./dez. 2011.

CULPEPER, J. Towards an anatomy of impoliteness. Journal of Pragmatics, v. 25, n. 3, p. 349-67, 1996.

Impoliteness and entertainment in the television quiz show: The Weakest Link. Journal of Politeness Research, v. 1, n. 1, p. 35-72, 2005.

- Reflections on impoliteness, relational work and power. In: BOUSFIELD, D.; LOCHER, M. A. (Eds.). Impoliteness in language: Studies on its interplay with power in theory and practice. Berlin and New York: Mouton de Gruyter, 2008. 3232-45, 2010.

Conventionalised impoliteness formulae. Journal of Pragmatics, v. 42, p.

; BOUSFIELD, D.; WICHMANN, A. Impoliteness revisited: with special reference to dynamic and prosodic aspects. Journal of Pragmatics, v. 35, p. 1545-79, 2003.

FONTANELLA, B. J. B.; LUCHESI, B. M.; SAIDEL, M. G. B. RICAS, J. TURATO, E. R.; MELO, D. G. Amostragem em pesquisas qualitativas: proposta de procedimentos para constatar saturação teórica. Cad. Saúde Pública, Rio de Janeiro, v. 27, n. 2, p. 388394, fev./ 2011.

FRASER. B. Conversational mitigation. Journal of Pragmatics, v. 4, p. 341-50, 1980.

1990.

. Perspectives on politeness. Journal of Pragmatics, v. 14, n. 2, p. 219-36,

GOFFMAN, E. On-face work - An analysis on ritual elements in social interactions. In: Interaction ritual - essays on face-to-face behaviour. Harmondsworth: Penguin Books, 1972 [1967].

A situação negligenciada. In: RIBEIRO, B. T.; GARCEZ, P. M. (Orgs.). Sociolinguística interacional: antropologia, linguística e sociologia em análise de discurso. Porto Alegre: AGE, 1998 [1964].

GRAHAM, S. L. Disagreeing to agree: Conflict, (im)politeness and identity in a computer-mediated community. Journal of Pragmatics, v. 39, p. 742-59, 2007.

GUMPERZ, J. J. On interactional sociolinguistic method. In: SARANGI, S.; ROBERTS, C. (Eds.). Talk, work and institutional order. Berlin: Mouton de Gruyter, 1999. 
HAUGH, M. Im/politeness, social practice and the participation order. Journal of Pragmatics, v. 58, p. 52-72, 2013.

HERITAGE, J.; RAYMOND, G. The Terms of Agreement: Indexing Epistemic Authority and Subordination in Talk-in-Interaction. Social Psychology Quarterly, v. 68, n. 1, p. 15-38, 2005.

HOLMES, J.; MARRA, M. Leadership and managing conflict in meetings. Pragmatics, v. 14, n. 4, p. 439-62, 2004.

HOLTGRAVES, T. The Linguistic Realization of Face Management: Implications for Language Production and Comprehension, Person Perception, and Cross-Cultural Communication. Social Psychology Quarterly, v. 55, n. 2, p. 141-59, 1992.

KERBRAT-ORECCHIONI, C. Análise da Conversação: princípios e métodos. Tradução de Carlos Piovezani Filho. São Paulo: Parábola, 2006 [1943].

Polidez e Impolidez nos debates políticos televisivos: o caso dos debates entre dois turnos dos presidentes franceses. In: SEARA, I. (Org.). Cortesia: olhares e (re)invenções. Lisboa: Chiado, 2014.

LAKOFF, R. The logic of politeness; or, minding your p's and q's. In: CORUM, C. et al. (Eds.). Papers from the Ninth Regional Meeting of the Chicago Linguistic Society, p. 292-305, 1973.

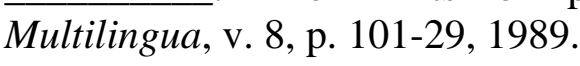

LEECH, G. Principles of Pragmatics. London: Longman, 1983.

The Pragmatics of Politeness. Oxford: Oxford University Press, 2014.

LERNER, G. H. Finding "Face" in the Preference Structures of Talk-in-Interaction. Social Psychology Quarterly, v. 59, n. 4, p. 303-21, 1996.

LOCHER, M. A. Relational work and interpersonal pragmatics. Journal of Pragmatics, v. 28, p. 138-51, 2013.

Interpersonal pragmatics and its link to (im)politeness research. Journal of Pragmatics, v. 86, p. 5-10, 2015.

; GRAHAM, S. L. Introduction to interpersonal pragmatics. In: (Eds.). Interpersonal Pragmatics. Mouton: Berlin, 2010.

MARCUSCHI, L. A. Marcadores conversacionais do português brasileiro: formas, posições e funções. In: CASTILHO, A. T. (Org.). Português culto falado no Brasil. Campinas: Editora da Unicamp, 1989.

Análise da conversação. 5. ed. São Paulo: Ática, 1999.

MARTINOVSKI, B. A framework for the analysis of mitigation in courts: Toward a theory of mitigation. Journal of Pragmatics, v. 38, p. 2065-86, 2006.

; MAO, W.; GRATCH, J.; MARSELLA, S. Mitigation Theory: An Integrated Approach. Proceedings of Cog Sci, Stresa, Italy, 2005. 
MARQUES, M. A. Quando a cortesia é agressiva. Expressão de cortesia e imagem do outro. In: OLIVEIRA, F.; DUARTE, I. M. (Orgs.). O Fascínio da Linguagem - Actas do Colóquio em Homenagem a Fernanda Irene Fonseca. Porto: CLUP, 2008.

MEIER, A. J. Defining politeness: universality in appropriateness. Language Sciences, v. 17 , n. 4 , p. $345-56,1995$.

MORGAN, M. The presentation of indirectness and power in everyday life. Journal of Pragmatics, v. 42, p. 283-91, 2010.

OCHS, E. Transcription as theory. In: JAWORSKI, A.; COUPLAND, N. The Discourse Reader. 2nd ed. USA: Routledge, 2006 [1984].

OPPENHEIM, F. E. Outline of a Logical Analysis of Law. Philosophy of Science, v. 11, n. 3, p. 142-60, Jul. 1944.

POMERANTZ, A. Preference in conversation: Agreeing and disagreeing with assessments. In: JAWORSKI, A.; COUPLAND, N. (Eds.). The Discourse Reader. 2nd ed. USA \& Canada: Routledge, 2006 [1984].

PRETI, D. Normas para transcrição dos exemplos. In: (Org.). Cortesia verbal. São Paulo: Humanitas, 2008.

SCHEGLOFF, E. A. On an Actual Virtual Servo-Mechanism for Guessing Bad News: A Single Case Conjecture. Social Problems, v. 35, n. 4, p. 442-57, 1988.

Talk and social structure. In: JAWORSKI, A.; COUPLAND, N. (Eds.). The Discourse Reader. 2nd ed. USA \& Canada: Routledge, 2006 [1991].

et al. The preference for self-correction in the organization of repair in conversation. Language, v. 53, n. 2, p. 361-82, 1977.

SIFIANOU, M. Disagreements, face and politeness. Journal of Pragmatics, v. 44, p. 1554-64, 2012.

TERKOURAFI, M. Beyond the micro-level in politeness research. Journal of Politeness Research, v. 1, n. 2, p. 237-62, 2005.

WATTS, R. J. Linguistic politeness research. Quo vadis? In: WATTS, R. J.; IDE, S.; EHLICH, K. (Eds.). Politeness in Language: Studies in its History, Theory and Practice. Berlin: Mouton, 2005.

\section{APÊNDICE}

\section{CONVENÇÕES DE TRANSCRIÇÃO}

\begin{tabular}{|l|l|}
\hline \multicolumn{1}{|c|}{ Ocorrência } & \multicolumn{1}{c|}{ Sinais } \\
\hline Nome dos participantes & Negrito \\
\hline Leitura de textos & “ $~$ \\
\hline Entonação ascendente & $\uparrow($ seta para cima) \\
\hline Entonação descendente & $\downarrow$ (seta para baixo) \\
\hline Pausa preenchida & eh, ah, hum... \\
\hline Pausa curta e pausa média & $().(.)$. \\
\hline
\end{tabular}




\begin{tabular}{|l|l|}
\hline Falas e/ou ações simultâneas & [[ (dois colchetes) \\
\hline Auto-interrupção & - \\
\hline Extensão de som curta & $:$ \\
\hline Ênfase / aumento de volume & MAIÚSCULA \\
\hline Frase / palavra acelerada & (ac.) e sublinhado \\
\hline Transcrição parcial ou eliminação de trecho & $/ . . . /$ \\
\hline Truncamento & $/$ \\
\hline Comunicação não verbal & $((\quad)$ ) (parênteses duplo) \\
\hline Aceno positivo de cabeça & $((+))$ \\
\hline Riso & $((\mathrm{R}))$ \\
\hline
\end{tabular}

Fontes: Atkinson \& Heritage (2006 [1984]); Ochs (2006 [1984]); Gumperz (1999) e Preti (2008). 